\title{
Different Location of Katanin P60 Effect on Cellular Microtubule Cutting
}

\author{
Li Shaojin, Luo Jianxian, Ji Zhisheng, Yang Yuhao, Zhang Guowei, Tan Minghui, Yang Hua*
}

Department of Orthopedics, the First Affiliated Hospital of Jinan University, Guangzhou, China

Email address:

qinminv07@qq.com (Yang Hua)

${ }^{*}$ Corresponding author

\section{To cite this article:}

Li Shaojin, Luo Jianxian, Ji Zhisheng, Yang Yuhao, Zhang Guowei, Tan Minghui, Yang Hua. Different Location of Katanin P60 Effect on Cellular Microtubule Cutting. Cell Biology. Vol. 7, No. 1, 2019, pp. 10-13. doi: 10.11648/j.cb.20190701.12

Received: August 12, 2019; Accepted: August 18, 2019; Published: September 19, 2019

\begin{abstract}
Katanin is a heterodimeric hydrolase belonging to the AAA protein family and its function is cutting microtubules. It plays an important role in cell division, neural development, cell migration, and the formation of motor organelles. Katanin has two subunits including katanin $\mathrm{p} 80$ and p60. This research is aimed to study the effect of different location of katanin p60 on cellular microtubule cutting. First, katanin p60 gene was amplified by PCR, and the eukaryotic recombinant plasmid GFP-katanin $\mathrm{p} 60$ and GFP- katanin $\mathrm{p} 60^{\mathrm{M} 1 \mathrm{~S}}$ were constructed. The recombinant plasmid was identified by enzyme digestion and sequencing. The expression of katanin in RFL- 6 cells was detected by western blot analysis. And, the distribution of katanin p60 in RFL-6 cells and its effect on microtubule were further examined. The results showed that the GFP-katanin p60 and GFP-katanin $\mathrm{p} 60^{\mathrm{M} 1 \mathrm{~S}}$ recombinant plasmids was successfully constructed. By western blot analysis, GFP-katanin p60 and GFP-katanin $\mathrm{p} 60^{\mathrm{M} 1 \mathrm{~S}}$ recombinant plasmids could be successfully expressed in RFL-6 cells. The microtubule cutting ability of GFP-katanin $\mathrm{p} 60^{\mathrm{M} 1 \mathrm{~S}}$ which distribute in whole-cell was stronger than GFP-katanin $\mathrm{p} 60$ which distribute in nuclear. Therefore, the cutting function on microtubule of katanin p60 depends on its distribution, and the whole cell distribution is beneficial to katanin p60 in cutting microtubule.
\end{abstract}

Keywords: Katanin p60, Microtubule Cutting, RFL-6 Cell, Protein Distribution

\section{Introduction}

Katanin is a heterodimeric hydrolase belonging to the AAA protein family [1]. It is ubiquitously expressed in plants and animals, mainly cutting tubulin. According to the molecular weight of the subunit, the smaller catalytic subunit named p60 is $60 \mathrm{KDa}$, and its role is cutting microtubules; the larger catalytic subunit is $80 \mathrm{KDa}$, named $\mathrm{p} 80$, the role of katanin p80 assisted p60 cutting microtubules [2-4]. Katanin plays an important role in cell division, neural development, cell migration, and the formation of motor organelles [5]. There are three Katanin-cut microtubule models, one of which is the combination of dynein and microtubule, which causes the microtubule structure to change, becoming "S" or "V" shape and thus is recognized as Katanin for cutting [6, 7]; Second models include dynamic instability mechanisms and the phenomenon of "size-dependent mobilization"[8, 9]; the third model is Katanin cutting post-translationally modified microtubules ${ }^{10}$. But, weather the distribution of katanin effect on its cutting function is not clear. Therefore, we constructed GFP-p60 and GFP-p60 ${ }^{\mathrm{M} 1 \mathrm{~S}}$ eukaryotic expression plasmids which distribute in nuclear and whole cell in RFL-6 cell to investigate their cutting function on microtubule, which provided a model basis for the subsequent overexpression of p60 gene cleavage research and its mechanism.

\section{Materials and Methods}

\subsection{Materials}

RFL-6 Cell was purchased from the shanghai Cell Bank. The types and manufactures of materials purchased are as follow: Dulbecco's Modified Eagle Medium (GIBCO), fetal bovine serum (GIBCO), Rabbit polyclonal antibody to GFP (abcam), rat monoclonal antibody to tubulin (abcam), Alexa Fluor 549 Donkey anti rat (abcam). EcoR I and BgI II Restriction enzyme, DNA marker, Homologous recombinant ligase, 2x Taq Plus Master Mix (TaKaRa). 


\subsection{Methods}

\subsubsection{Construction of GFP-p60, GFP-p60 ${ }^{M 1 S}$ Recombinanat Plasmid}

According to Rat p60 gene sequence in Gene Bank, designing primers for PCR of GFP-p60 in table 1. Rat cDNA as the template, the conditions for PCR were as follows: pre-denaturation at $95^{\circ} \mathrm{C}$ for $3 \mathrm{~min}, 35$ cycles of denaturation at $95^{\circ} \mathrm{C}$ for $30 \mathrm{~s}$, annealing at $59^{\circ} \mathrm{C}$ for $30 \mathrm{~s}$ and extension at $72^{\circ} \mathrm{C}$ for $90 \mathrm{~s}$, and a final extension at $72^{\circ} \mathrm{C}$ for $5 \mathrm{~min}$. Recycling the PCR products were used to harvest katanin p60 and p60M1S, BgI II and EcoR I restriction endonucleases were used to treat pEGFP-C1. In the presence of Homologous recombinant ligase, katanin $\mathrm{p} 60$ and $\mathrm{p} 60^{\mathrm{MIS}}$ were connected at $37^{\circ} \mathrm{C}$ for $30 \mathrm{~min}$ and transfected into $\mathrm{E}$ coli. Identification of these plasmids was done by digestion with restriction endonucleases and subsequent sequencing.

Table 1. Primers of constructed plasmids.

\begin{tabular}{|c|c|c|}
\hline Plasmid & Sequence & \\
\hline \multirow{2}{*}{$\begin{array}{l}\text { GFP-Katanin } \\
\text { p60 }\end{array}$} & Forward & $\begin{array}{l}\text { 5'-TACAAGTCCGGACTCAGATCTA } \\
\text { TGAGTCTTCTAATGATTACTGAGA } \\
\text { ATGTA-3, }\end{array}$ \\
\hline & Reverse & $\begin{array}{l}\text { 5'-GTACCGTCGACTGCAGAATTCT } \\
\text { TACATTCTCAGTAATCATTAGAAG } \\
\text { ACTCA-3' }\end{array}$ \\
\hline \multirow{2}{*}{$\begin{array}{l}\text { GFP-Katanin } \\
\text { p } 60^{\mathrm{M} 1 \mathrm{~S}}\end{array}$} & Forward & $\begin{array}{l}\text { 5'-TACAAGTCCGGACTCAGATCTT } \\
\text { CCAGTCTTCTAATGATTACTGAGA } \\
\text { ATGTA-3' }\end{array}$ \\
\hline & Reverse & $\begin{array}{l}\text { 5'-GTACCGTCGACTGCAGAATTCT } \\
\text { TACATTCTCAGTAATCATTAGAAG } \\
\text { ACTCA-3, }\end{array}$ \\
\hline
\end{tabular}

\subsubsection{Culture and Transfection of RFL-6 Cell}

RFL-6 cell were routinely cultured. GFP、GFP-katanin p60 and GFP-katanin $\mathrm{p} 60^{\mathrm{M} 1 \mathrm{~S}}$ were used to transfect RFL- 6 cell with Lipo2000. Immunofluorescence staining and western blot assay were performed.

\subsubsection{Detection of Protein Expression by Western Blot Assay}

At 48h after transfection with GFP、GFP-katanin p60 and GFP-katanin p60 ${ }^{\mathrm{M} 1 \mathrm{~S}}$, RFL-6 cells were harvested, washed with cold PBS twice, lysed in lysis buffer on ice for $10 \mathrm{~min}$, and then centrifuged at $12000 \mathrm{r} / \mathrm{min}$ for $15 \mathrm{~min}$ at $4{ }^{\circ} \mathrm{C}$. The supernatant was collected and protein quantification was done by using coomassie brilliant blue. The protein concentration was calculated. Then, total proteins were subjected to $10 \%$ SDS-PAGE $(50 \mu \mathrm{g} / \mathrm{lane})$ and then transferred onto $0.45 \mu \mathrm{m} \mathrm{NC}$ membrane which was subsequently blocked, treated with anti-GFP antibody and horseradish peroxidase conjugated secondary antibody. Visualization was done with ECL, and protein bands were scanned.

\subsubsection{Fluorescent Immunocytochemistry}

After calcium phosphate mediated transfection, cells were harvested, fixed in $4 \%$ paraformaldehyde, treated with perforating agent twice ( $5 \mathrm{~min}$ for each), and blocked in 5\% donkey serum for $1 \mathrm{~h}$ at room temperature. Then, these cells were incubated with primary antibody at $4^{\circ} \mathrm{C}$ overnight and washed with TBST $(0.1 \%$ TritonX-100 in TBS). Following incubation with secondary antibody, cells were washed with TBST (0.1\%TritonX-100 in TBS). After DAPI staining, the coverslips containing cells were air-dried and mounted, and then observed under a laser scanning confocal microscope. Image-Proplus software was used to detect the content of microtubules in RFL-6 cells.

\subsubsection{Statistical Analysis}

The images of RFL- 6 cells were collected by laser confocal microscope, and the images of Hela cells were transferred into Image $\mathrm{J}$ for processing. Each group was set up with double blindness and repeated three times independently. At least 30 cells were counted in each group of RFL-6 cells, and all the data were expressed in mean \pm SD. SPSS 17.0 software and One-way ANOVA method were used to carry on the correlation statistical analysis, *representing $\mathrm{P}<0.05$, the difference was statistically significant.

\section{Results}

\subsection{Construction, Identification and Sequencing of Two Recombinant Plasmids GFP-katanin p60 and GFP-katanin p60 ${ }^{M 1 S}$}

According to design primers get katanin p60 and katanin $\mathrm{p} 60^{\mathrm{M} 1 \mathrm{~S}}$, and then connected to pEGFP-C1 which treated by BgI II and EcoR I. The positive monoclonal culture was selected from the culture plate and incubated over-night. The plasmids were extracted by enzyme digestion (Figure 1) and sequenced to ensure that the recombinant plasmids were not mutated, deleted or mislocated.
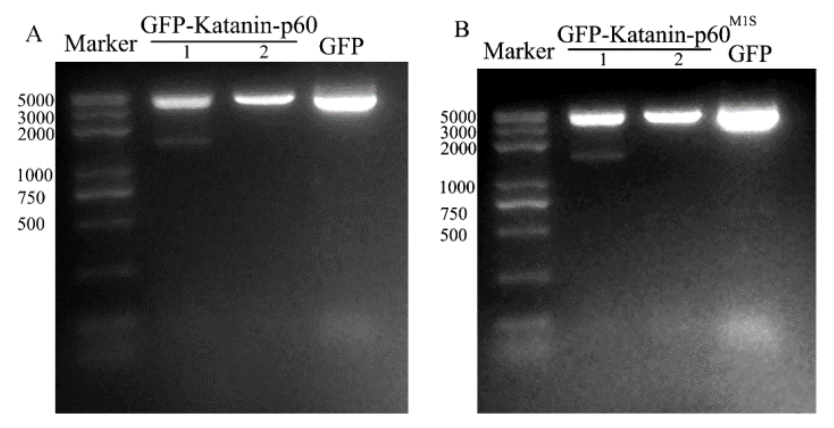

Figure 1. Identification of eukaryotic plasmids of GFP-katanin p60 and GFP-katanin $p 60^{M 1 S}$.

A: GFP-p60 recombinant plasmids; B: GFP-p $60^{\mathrm{M} 1 \mathrm{~S}}$ recombinant plasmids. Lane 1: DNA Marker; Lane 2: Results of double enzyme digestion; Lane 3: Single enzyme digestion; Lane 4: Empty plasmid digestion.

\subsection{Expression of GFP-katanin p60 and GFP-katanin p60 ${ }^{M 1 S}$}

RFL-6 cell were routinely cultured and transfected with GFP, GFP-katanin p60 and GFP-katanin p60 ${ }^{\mathrm{M} 1 \mathrm{~S}}$. In control group, cell transfected with GFP. But, in the experimental group, cell transfected with GFP-katanin p60 and GFPkatanin $\mathrm{p} 60^{\mathrm{M} 1 \mathrm{~S}}$ respectively. After $48 \mathrm{~h}$ transfection, according 
to western blot detecting those proteins (Figure 2).

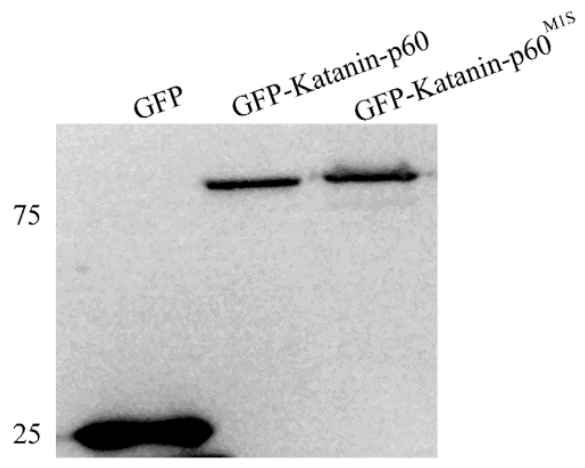

Line 1 GFP; Line2 GFP-p60; Line 3 GFP-p60 ${ }^{\mathrm{M} 1 \mathrm{~S}}$

Figure 2. Expression of GFP-katanin p60 and GFP-katanin $p 60^{M I S}$.

\subsection{Microtubule Cutting of RFL-6 Cell by GFP-katanin p60 and GFP-katanin p60}

To observe the microtubule cutting efficiency of RFL- 6 cells by GFP-katanin p60 and GFP-katanin p60 $11 \mathrm{~S}$, we transfected them into RFL- 6 cells respectively, and cultured for $24 \mathrm{~h}$. After stained with immunofluorescence, RFL- 6 cell observed under confocal microscope. The microtubules of RFL- 6 cells in the experimental group of GFP-katanin $\mathrm{p} 60^{\mathrm{M} 1 \mathrm{~S}}$ were depolymerized and cut into small pieces, but the other groups were not. In addition, the fluorescence intensity of the microtubules of the RFL-6cells in the GFP-katanin $\mathrm{p} 60^{\mathrm{M} 1 \mathrm{~S}}$ group was significantly weaker than GFP- katanin p60 group. The results showed that overexpression of GFP-p $60^{\mathrm{M} 1 \mathrm{~S}}$ had a remarkable microtubule cutting effect on RFL-6 cells (Figure 3 ).
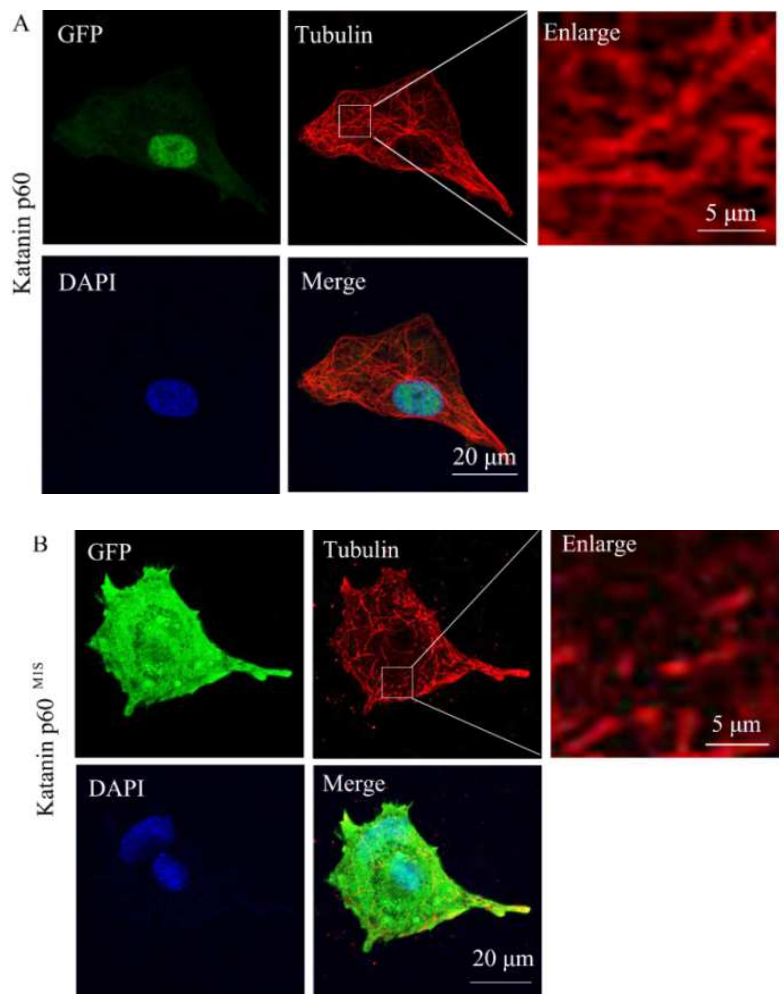

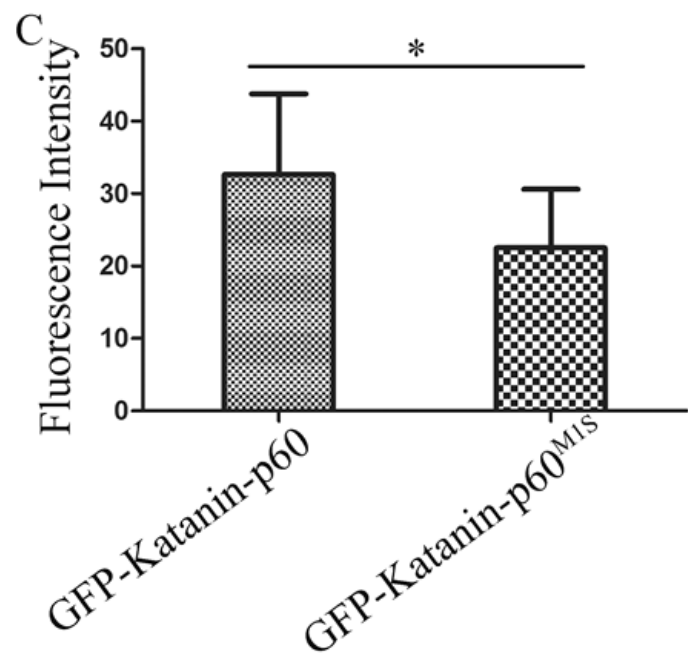

Figure 3. Analysis of overexpression GFP-katanin p60, GFP-katanin p60 $0^{M 1 S}$ in RFL-6 cell by immunofluorescence.

(A) and (B) Immunostaining for GFP (green), tubulin (red) and DAPI (blue) in katanin p60 and katanin p60 ${ }^{\mathrm{M} 1 \mathrm{~S}}$ in RFL-6 cell. Scale bar $10 \mathrm{um}$ and $2 \mathrm{um}$. (C) Quantification of microtubule intension for the experiment shown in (A), microtubule intension in 20 cell were measured per condition. Date represent mean $\pm \mathrm{SD}, \mathrm{P}<0.05$.

\section{Discussion}

Katanin, spastin, and fidgetin are all microtubule-cleaved proteins $[11,12]$. At present, two kinds of microtubule cutting proteins including katanin and spastin have been studied widely. These two proteins are mainly bound to stable microtubules, which are primarily regulated by acetylated or poly-glutamylated post-translational modified tubulin [13-15]. Fidgetin mainly combines with deacetylated microtubule which was first discovered in sea urchins in 1993 [16]. It can be used to cleave microtubule by ATP, katanin consists of katanin p 80 and katanin p60 which is capable of catalyzing the hydrolysis of ATP to cleave microtubules [2-4]. To study the distribution of katanin p60 in cells and the ability to cleave microtubules, the katanin p60 gene was amplified by PCR, and then the katanin p60 gene was transferred into the eukaryotic vector. The results showed that the size of the product after PCR was consistent with katanin p60. And, the sequencing results showed that the katanin p60 gene had no mutation. The above results show that the recombinant plasmid of katanin p60 was successfully constructed.

In order to confirm that the recombinant plasmid can correctly express p60 protein, the control vector plasmid GFP, recombinant plasmid GFP-katanin p60, GFP-katanin p60 1 1S were transiently transfected RFL- 6 cell for $24 \mathrm{~h}$, and western blot results showed two recombinant plasmids both expressed the specific target band at $85 \mathrm{kDa}$, but the control vector had only one target band at $25 \mathrm{kDa}$. Katanin p 60 is encoded by 419 amino acids and has a molecular weight of approximately 60 $\mathrm{kDa}$. Therefore, the results indicate that both recombinant plasmids can accurately express katanin p60 protein.

In order to confirm the distribution and function of katanin p60 in cells, the control vector GFP, recombinant plasmid 
GFP-katanin p60, GFP-katanin p60 1 1S were transiently transfected into RFL- 6 cells for $24 \mathrm{~h}$. The results showed that wild-type katanin p60 was mostly located in the nucleus, protein expression was mainly concentrated in the nucleus, and another recombinant plasmid expressed katanin $\mathrm{p} 60^{\mathrm{M} 1 \mathrm{~S}}$ protein in whole cells. The reason for the difference in distribution may be that this study mutated the initiation codon ATG to TCC. It has been reported in the literature that the initiation codon mutation does not affect the expression and function of p60 protein [17]. Similar to the control vector in whole cell distribution, the ability to cleave microtubules showed that the whole cell distribution of the recombinant plasmid was significantly stronger than the wild type katanin p60. The katanin p60 has a weaker cutting ability than spastin. The katanin p60 protein accumulated in the nucleus does not destroy the cytoskeleton efficiently. However, the whole cell-distributed katanin p60 protein is more likely to destroy the cytoskeleton.

\section{Conclusion}

In summary, as a member of the microtubule-cleaving protein family, the cutting function on microtubule of katanin p60 depends on its distribution. The katanin p60 accumulated in the nucleus does not destroy the cytoskeleton efficiently, but the whole cell distribution is beneficial to katanin p60 in cutting microtubule.

\section{Acknowledgements}

The authors declare no conflict of interest. This work was supported by National Natural Science Foundation of China (81771331 and 31900691), Natural Science Foundation of Guangdong Province, China (2017A030313595), Guangzhou science and technology project (201605130849016) and Project funded by China Postdoctoral Science Foundation (2019M653292).

\section{References}

[1] Frickey T, Lupas AN. Phylogenetic analysis of AAA proteins. Journal of structural biology. 2004; 146 (1-2): 2-10.

[2] Hartman JJ, Mahr J, McNally K, et al. Katanin, a microtubule-severing protein, is a novel AAA ATPase that targets to the centrosome using a WD40-containing subunit. Cell. 1998; 93 (2): 277-287.

[3] McNally FJ, Vale RD. Identification of katanin, an ATPase that severs and disassembles stable microtubules. Cell. 1993; 75 (3): 419-429.
[4] McNally KP, Bazirgan OA, McNally FJ. Two domains of p80 katanin regulate microtubule severing and spindle pole targeting by p60 katanin. Journal of cell science. 2000; 113 (Pt 9): 1623-1633.

[5] Ghosh DK, Dasgupta D, Guha A. Models, Regulations, and Functions of Microtubule Severing by Katanin. ISRN molecular biology. 2012; 2012: 596289.

[6] Davis LJ, Odde DJ, Block SM, et al. The importance of lattice defects in katanin-mediated microtubule severing in vitro. Biophysical journal. 2002; 82 (6): 2916-2927.

[7] Mohrbach H, Kulic IM. Motor driven microtubule shape fluctuations: force from within the lattice. Physical review letters. 2007; 99 (21): 218102.

[8] Allard JF, Wasteneys GO, Cytrynbaum EN. Mechanisms of self-organization of cortical microtubules in plants revealed by computational simulations. Molecular biology of the cell. 2010; 21 (2): 278-286.

[9] Baas PW, Karabay A, Qiang L. Microtubules cut and run. Trends in cell biology. 2005; 15 (10): 518-524.

[10] Sudo H, Baas PW. Acetylation of microtubules influences their sensitivity to severing by katanin in neurons and fibroblasts. The Journal of neuroscience : the official journal of the Society for Neuroscience. 2010; 30 (21): 7215-7226.

[11] Fletcher DA, Mullins RD. Cell mechanics and the cytoskeleton. Nature. 2010; 463 (7280): 485-492.

[12] Zhang D, Rogers GC, Buster DW, et al. Three microtubule severing enzymes contribute to the "Pacman-flux" machinery that moves chromosomes. The Journal of cell biology. 2007; 177 (2): 231-242.

[13] Bailey ME, Sackett DL, Ross JL. Katanin Severing and Binding Microtubules Are Inhibited by Tubulin Carboxy Tails. Biophysical journal. 2015; 109 (12): 2546-2561.

[14] Tao J, Feng C, Rolls MM. The microtubule-severing protein fidgetin acts after dendrite injury to promote their degeneration. 2016; 129 (17): 3274-3281.

[15] Taylor JL, White SR, Lauring B, et al. Crystal structure of the human spastin AAA domain. Journal of structural biology. 2012; 179 (2): 133-137.

[16] Austin TO, Matamoros AJ, Friedman JM, et al. Nanoparticle Delivery of Fidgetin siRNA as a Microtubule-based Therapy to Augment Nerve Regeneration. Scientific reports. 2017; 7 (1): 9675 .

[17] Karabay A, Yu W, Solowska JM, et al. Axonal growth is sensitive to the levels of katanin, a protein that severs microtubules. The Journal of neuroscience : the official journal of the Society for Neuroscience. 2004; 24 (25): 5778-5788. 